\title{
Commentary: we need to be better prepared for a technological future
}

\author{
Bertalan Mesko medical futurist
}

Budapest, Hungary

\begin{abstract}
A few times a week, I put a small device into a pocket on a wristband and measure my sleep pattern. I use the results to set my smart watch to wake me up at the optimum time (when I start moving and I'm not in deep sleep any more). That way I wake up energised. When I go out for a run I collect data with activity trackers and wear a chest strip to chart my heart rate to motivate me to improve my performance. Once a week, I measure my blood pressure, and I can do an echocardiogram at home. From home I also access the peer reviewed literature and look at information sourced from my curated social media channels. For relaxation I use a device that gives feedback about my brain activity, and I improve my cognitive skills by playing neuroscience validated online games. Once a month I check if I am eating too fast with a smart fork (www.hapi.com/product/ hapifork). Does it sound obsessive? My lifestyle is not even at the end of the scale.
\end{abstract}

Chris Dancy, described in Businessweek as possibly the most connected human on earth, has hundreds of sensors on his body and a smart home that can dim the lights and start playing classical music when he is getting stressed. ${ }^{1}$ There are people living with augmented reality cameras in their eyes and magnetic implants in their fingertips that allow them to remotely unlock a smart phone or a garage door. These examples are among myriad new technologies and innovations coming on stream that collectively will not only enable people to manage their health but are set to tear down the ivory tower of medicine too (box).

To prepare for the future, doctors and patients must change. All need to acquire digital literacy skills, get to grips with new technologies, and use new channels of communication. Doctors will need to develop their role as guides for patients struggling in the digital jungle. Digital methods are available for all of us to tackle information overload, from subscribing to RSS feeds to using Twitter for crowdsourcing (www.youtube.com/watch? $\mathrm{v}=-\mathrm{x} 7 \mathrm{~S} 6 \mathrm{scaU} 2 \mathrm{w}$ ).

Another task for health professionals is to ensure rigorous evaluation of new technologies and ensure patients are aware of their risks and limitations as well as their potential benefits. For their part, patients must meet physicians half way and take more responsibility for their own health and managing their conditions. For both, the quality of the doctor-patient relationship will remain central. Innovations will increase the quality and affordability of care, but this should not be at the expense of maintaining the human touch.

Enabling people to own and understand their health data is important. It is outrageous that many hospitals and practices still don't have joined up e-records and doctors are not equipped to handle new streams of data. When I brought my smart phone with infographics about my vital sign measurements to show to my general practitioner, he did not know what to do with the data or how to transmit the otherwise useful and quality data to the medical record systems. Young doctors are learning new skills, however. At Semmelweis Medical School in Hungary they have been taught about the use of social media, mobile devices, and wearable gadgets for health and medical purposes since 2008 .

If the waves of change from disruptive technologies and a restructured medical ecosystem hit us unprepared, which is the situation we are in now, there is a risk that medicine will become even more of a technology based service. To prevent this, we should be consciously and purposefully redesigning health systems by preparing for the now.

Competing interests: I have read and understood BMJ policy on declaration of interests and have no relevant interests to declare.

Provenance and peer review: Commissioned; not externally peer reviewed.

1 Broudway I. Is Chris Dancy the most quantified self in America? Businessweek 2014 Jun in-america. 


\section{New health technologies \\ Gamifying health \\ WellaPets (www.wellapets.com) \\ Re-Mission 2 (www.re-mission2.org) \\ Empowered patients \\ Smart Patients (www.smartpatients.com) \\ E-patients (http://e-patients.net/)}

\section{Telemedicine and remote care}

InTouch Health (www.intouchhealth.com)

American Well (www.americanwell.com)

Surgical and humanoid robots

Boston Dynamics (www.bostondynamics.com)

DaVinci Surgery (www.davincisurgery.com)

Genomics and personalised medicine

NanoPoreTech (www.nanoporetech.com)

Gentle (https://gentlelabs.com)

\section{Body sensors}

MC10 (www.mc10inc.com)

Equivital (http://www.equivital.co.uk)

$3 D$ printing revolution

Not Impossible Labs (www.notimpossiblelabs.com/)

3D Systems (www.3dsystems.com)

Powered exoskeletons and prosthetics

BeSpoke Inonvations (www.bespokeinnovations.com)

RoboHand (www.robohand.net)

Medical decisions via artificial intelligence

IBM Watson (www.ibm.com/smarterplanet/us/en/ibmwatson) 